\title{
Research Paper: The Effectiveness of Neurological Music Intervention on Psychological Well-Being of Women With Multiple Sclerosis
}

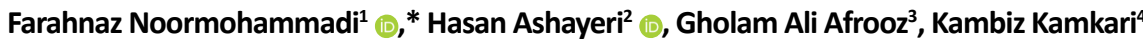

1. Department of Psychology, Faculty of Literature Humanities and Social Sciences, Science and Research Branch, Islamic Azad University, Tehran, Iran.

2. Department of Neurology and Psychiatry, School of Medicine, Iran University of Medical Sciences, Tehran, Iran.

3. Department of Psychology, Faculty of Psychology and Education, University of Tehran, Tehran, Iran.

4. Department of Educational Sciences, Faculty of Education and Psychology, Islamshahr Branch, Islamic Azad University, Tehran, Iran.

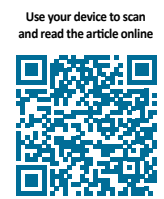

Cftertion Noormohammadi, F, Ashayeri H, Afrooz GhA, Kamkari K. [The Effectiveness of Neurological Music Intervention on Psychological Well-Being of Women With Multiple Sclerosis (Persian)]. Archives of Rehabilitation. 2019; 20(1):74-85. http:// dx.doi.org/10.32598/rij.20.1.74

http://dx.doi.org/10.32598/rj.20.1.74

Received: 27 Oct 2018

Accepted: 25 Feb 2019

Available Online: 01 Apr 2019

\section{ABSTRACT}

Objective Multiple Sclerosis (MS) is a chronic autoimmune, demyelinating disorder of the central nervous system. Psychological well-being often declines as a consequence of this impairment. Application of neurological musical intervention to adapt with the limitation of neurological impairments has been under investigation. This study aimed to explore the effectiveness of neurological music intervention on the psychological wellbeing of women with MS.

Materials \& Methods Quasi-experimental study with pretest and posttest design was conducted. A total of 20 women from the Iranian MS Association, with a relapsing-remitting course, aged 20 to 30 years, were selected with the convenience sampling method. After grouping them with respect to variables such as education, age, marital status, occupation, and low Extended Disability Status (EDSS), they were randomly paired and assigned to experimental and control groups after obtaining their consent and taking the pretest. The exclusion criteria for the participants were as follows: psychological symptoms such as depression or taking other musical training during the intervention. Neurological music intervention was designed with the assistance of a musician based on Iranian culture and Musical Executive Function Training (Thaut, 2005) to affect the frontal and prefrontal lobes. The 8 designations of the training program included "executive function", "goal regulation support", "group motivation", "impulsivity control", "inhibition", "responsibility", "problem-solving creativity", and " decision making/creativity". The internal validity of program has been already validated. The experimental group received 30 sessions training, two times a week for three months in MS association center while the control group did not receive any training. Scores were gathered using Ryff (1995) 42-item psychological well-being scale in the pretest and posttest stages. Also, the Kurtke (1983) extended disability status scale was used to evaluate the physical disabilities of MS participants.

Results The results, analyzed in ANCOVA and MANCOVA, indicated a significant improvement in psychological well-being $(P<0.05)$ and medium effect size $(0.38)$ according to the Cohen Scale. No significant improvement in 6 Ryff subscales was observed but a small effect was noted in self-acceptance (0.02), personal growth $(0.02)$, the purpose of life (0.01), environmental mastery (0.07), autonomy (0.09), and small to medium size effect in positive relation $(0.23)$

Conclusion According to experts, there is no cure for multiple sclerosis, there are, however, numerous treatments and rehabilitation interventions to slow down and reduce the physical and psychological symptoms. These findings suggest that neurological music intervention based on "Musical Executive Function Training" has a potential dual effect on cognitive and affective aspects of the brain. This kind of music intervention includes group and individual improvisation and composition exercises which improved the executive function skills such as organizing, problem-solving, decision making, and comprehending. Our results indicate that neurological music intervention improves psychological well-being in women with MS. Although there was no significant effect on the subscale of psychological wellbeing, a small to medium size effect was observed on different subscales of well-being. It appears that this intervention can be applied to clinical and rehabilitation settings.
Keywords:

Neurological music intervention, Psychological wellbeing, Multiple Sclerosis

\section{* Corresponding Author:}

Hasan Ashayeri, MD

Address: Department of Neurology and Psychiatry, School of Medicine, Iran University of Medical Sciences, Tehran, Iran.

Tel: +98 (901) 7300969

E-Mail: neourosientice@yahoo.com 


\title{
اثربخشى مداخله موسيقى عصبشناختى بر بهزيستى روانشناختى زنان مبتلا به اسكروزيس קندكانه
}

\author{
فرحناز نورمحمدى' هـ "خسن عشايرى 'ه، غلامعلى افروز"، كامبيز كامكارى" \\ 1 - كروه روانش شناسى، دانشكده ادبيات، علوم انسانى واجتماعى، واحد علوم و تحقيقات، دانشكاه آزاد اسلامي، تهران، ايران.

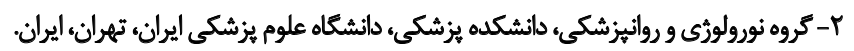

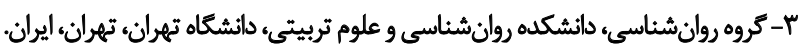

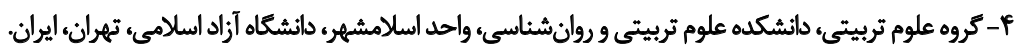

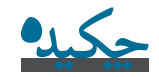

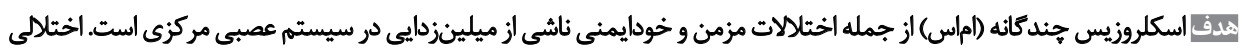

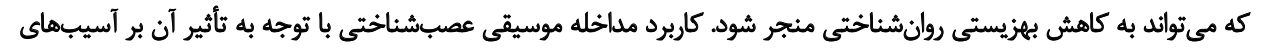

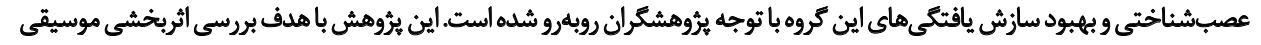

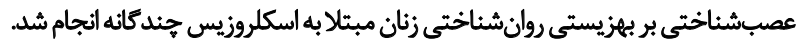

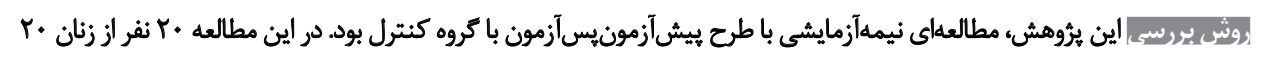

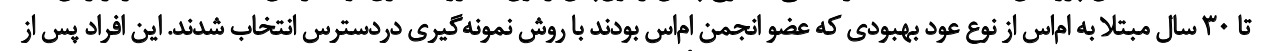

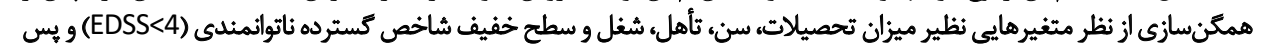

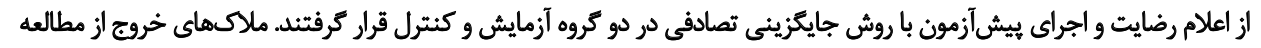

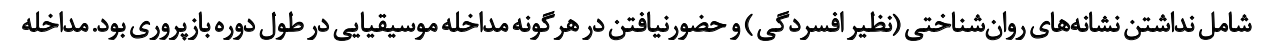

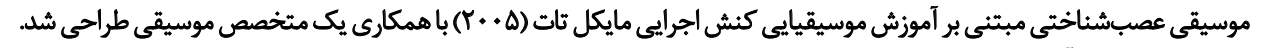

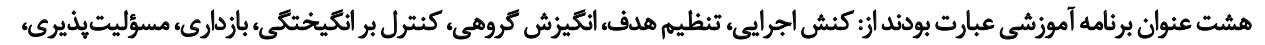

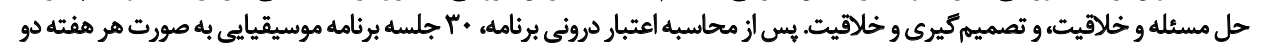

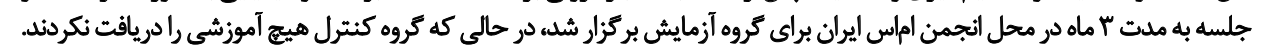

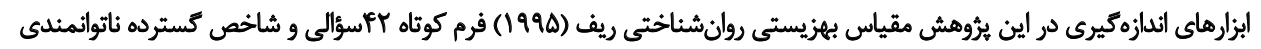

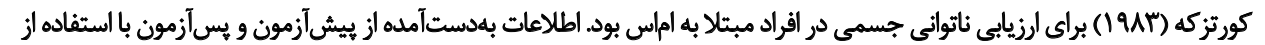

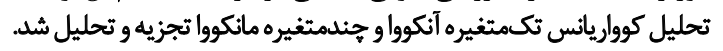

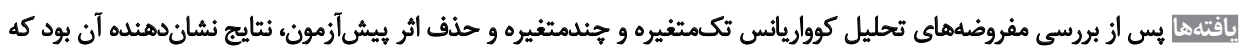

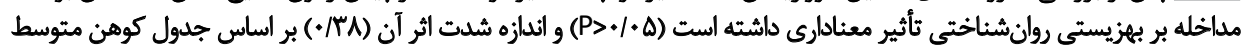

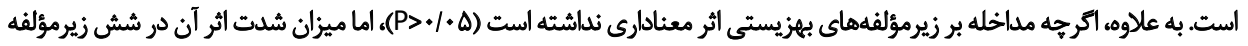

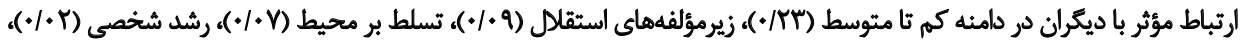

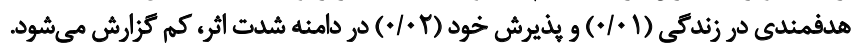

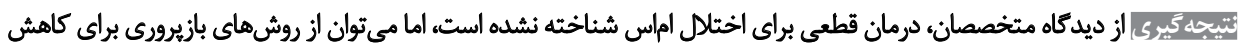

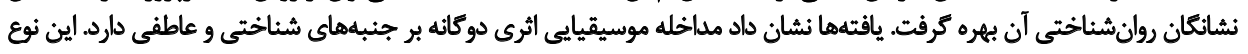

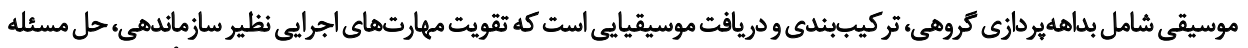

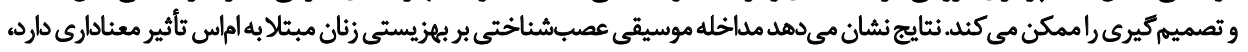

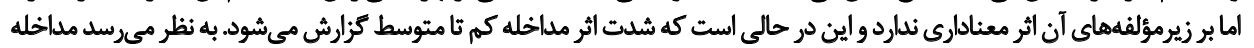

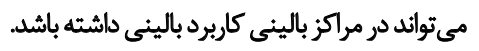

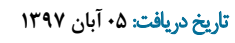

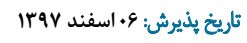
تاريخ انتشار: rا فروردين

$$
\text { مليديدوازٔهها: }
$$


هدفمندى در زندكى، رشد شخصى، داشتن روابط مؤثر باديكران،

مقدمه

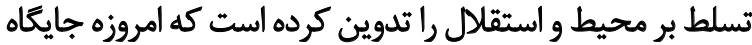

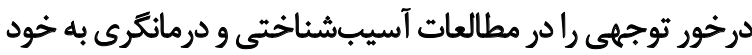

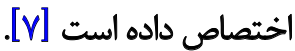

از سوى ديكَر، اين بُؤوهشَّران بر بايه مطالعات مبتنى بر وجود

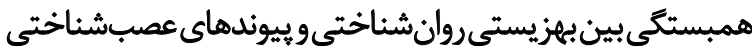

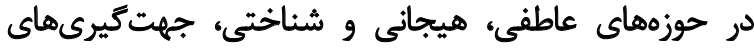

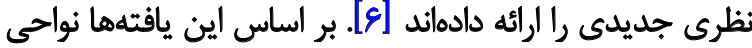

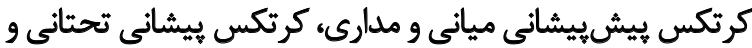

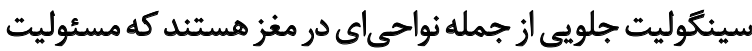

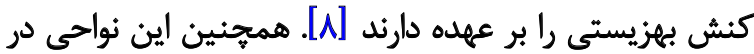

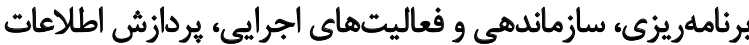

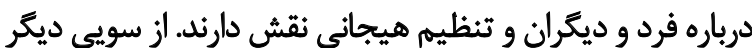

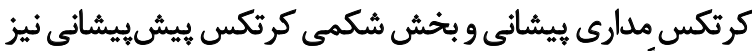

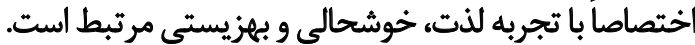

تحقيقات در قلمرو بهزيستى روانشناختى حاكى ازئ يايينبودن

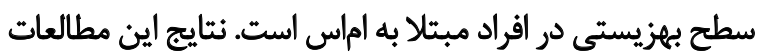

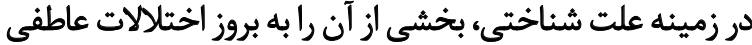

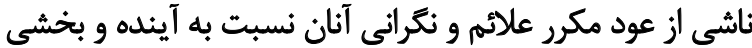

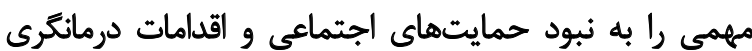

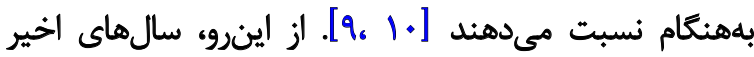

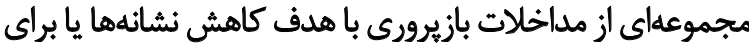

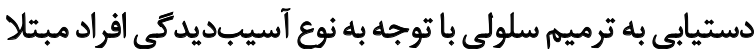

به اماس انجام شده است [11]]

مداخله موسيقى عصبشناختى "از جمله مداخلات موسيقيايى مايى

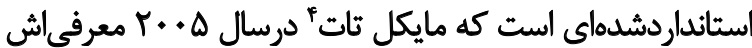

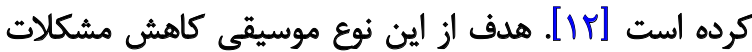

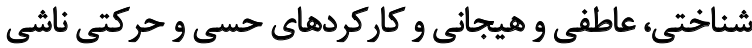

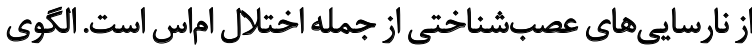

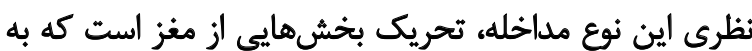

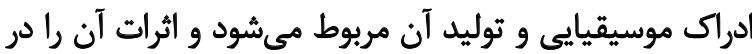

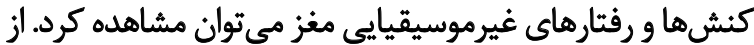

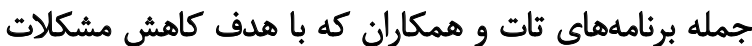

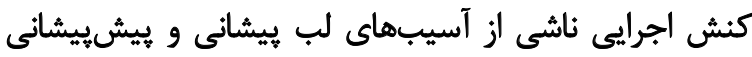

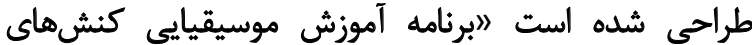

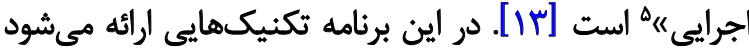

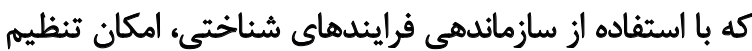

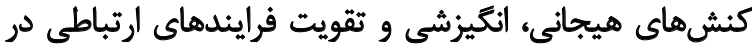

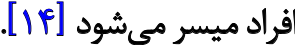
افراد مبتلا به اماس نارسايىهاى جندكانهاي را تجربه مي كنيد

اختلال اماس از شايعترين اختلالات عصبشناختى ناشى از

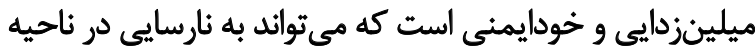

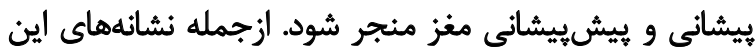

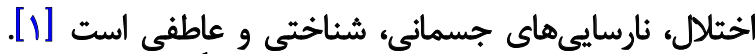

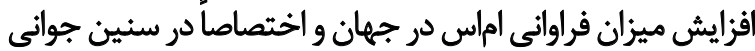

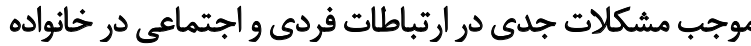

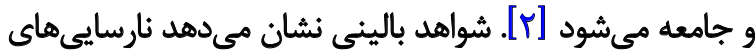

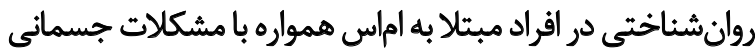

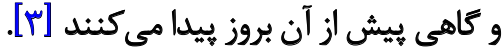

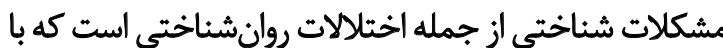

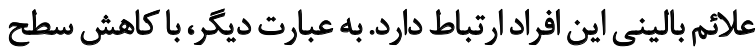

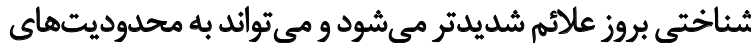

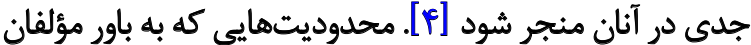

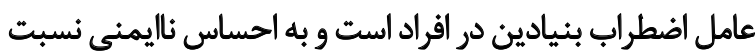

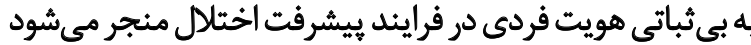

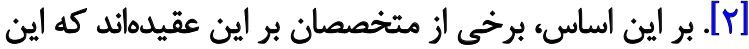

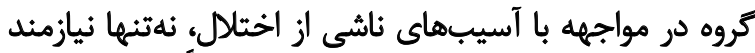

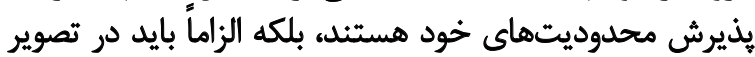

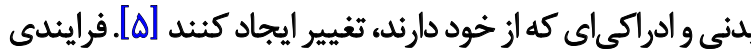

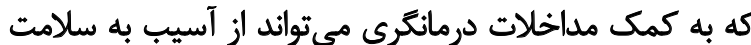

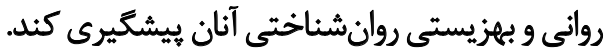

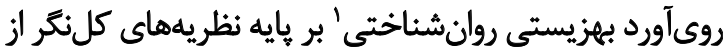

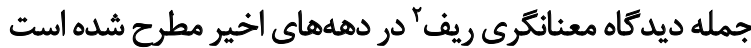

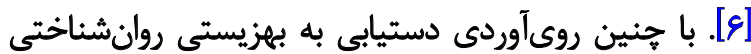

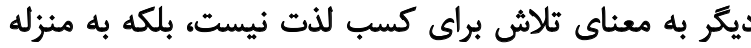

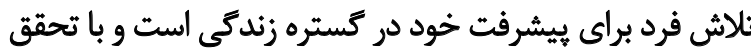

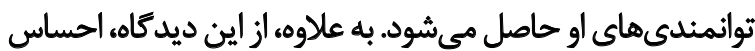

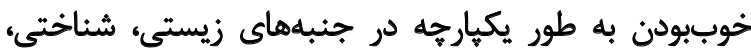

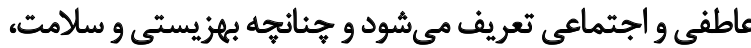

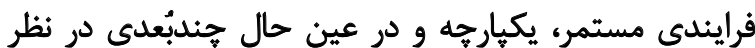

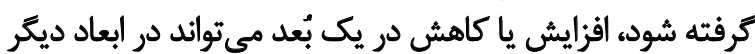

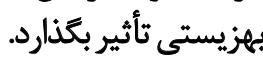

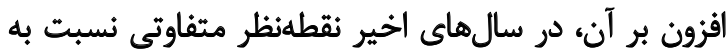

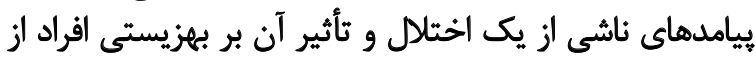

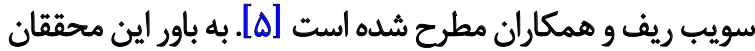

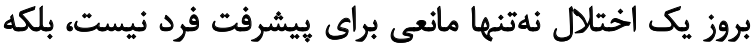

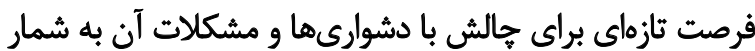

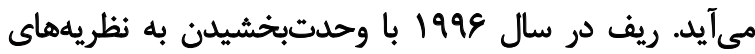
مختلف، شش مؤلفه بهزيستى خود شامل بذيرش خائ خودي، 


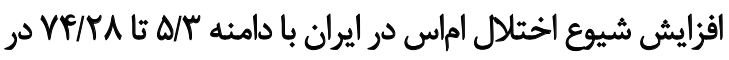

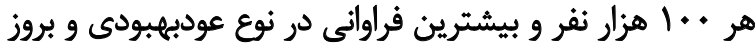

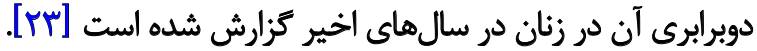

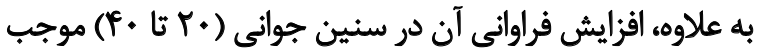

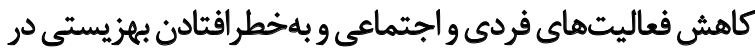

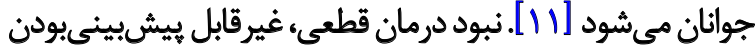

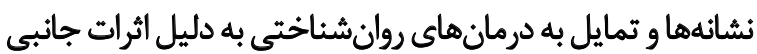

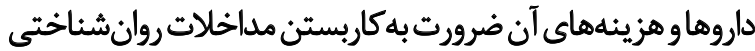

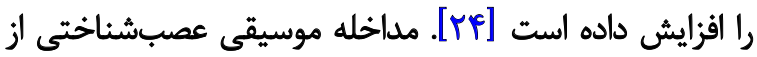

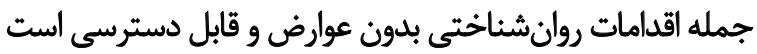

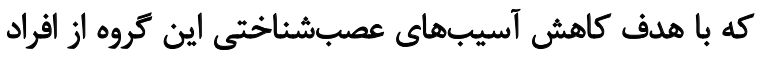

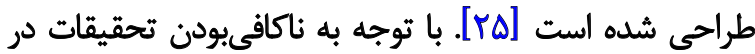

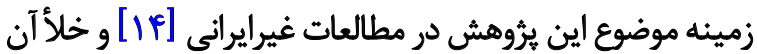

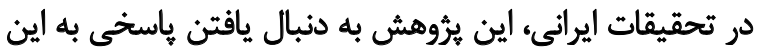

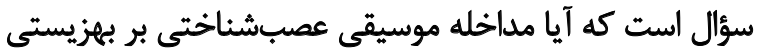
روانشناختى زنان مبتلا به اماس مؤثر است.

\section{ووشُ بورسي}

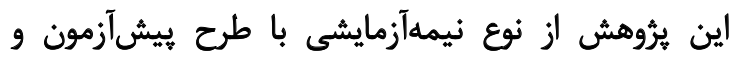

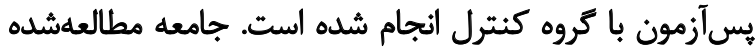

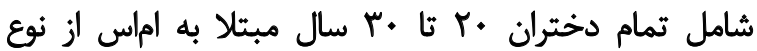

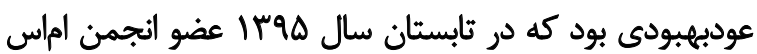

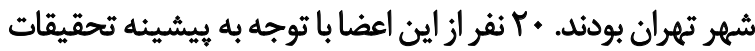

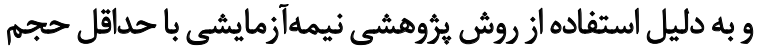

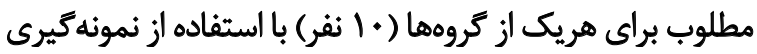

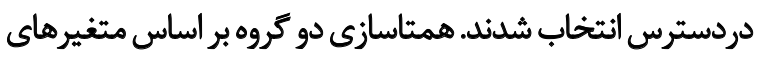

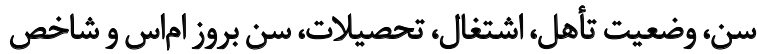

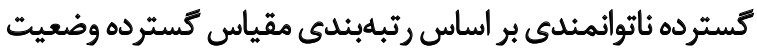

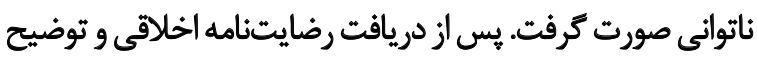

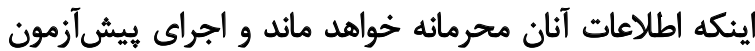

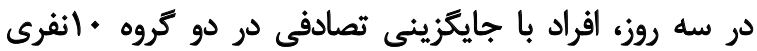

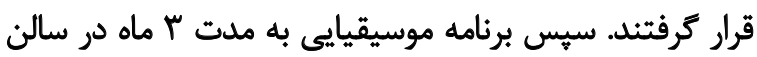

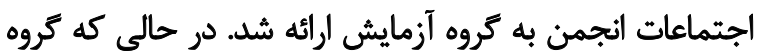

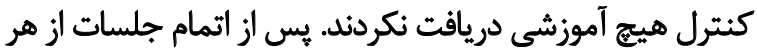

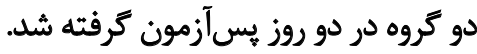

ملاكهاى ورود به برنامه عبارت بود ازي: ابتلا به اماس از نور

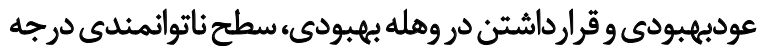

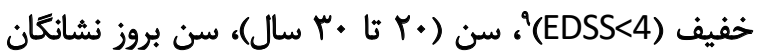

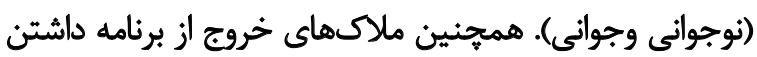

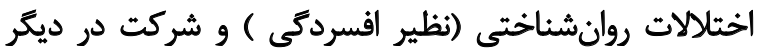

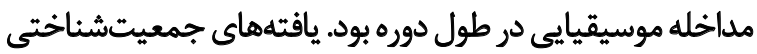

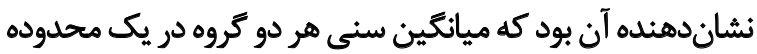

9. Extended Disability Status Scale (EDSS)
كه ناشى از آسيبهاى متعدد عصبشناختى است. ماهيت

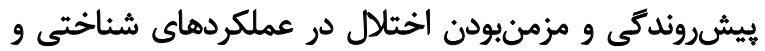

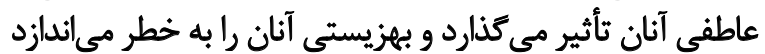

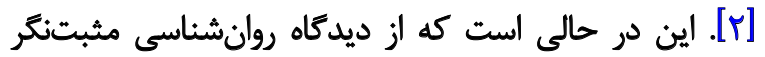

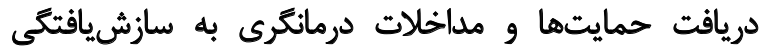

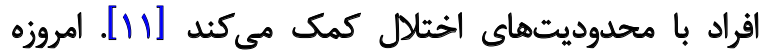

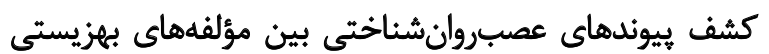

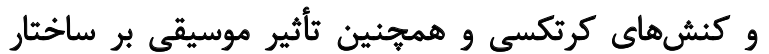

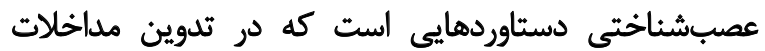

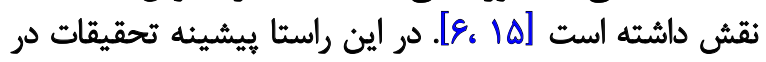

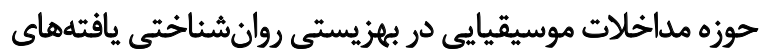
متناقضى را نشان مي دهد [19]

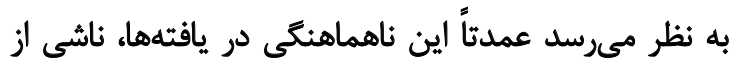

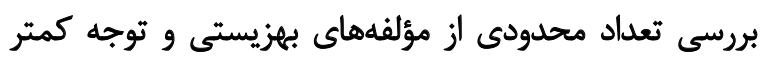

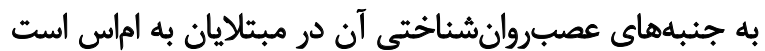

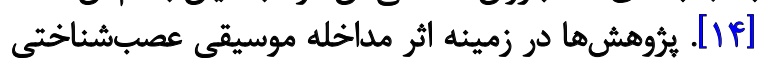

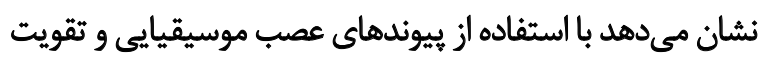

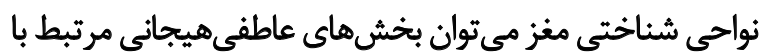

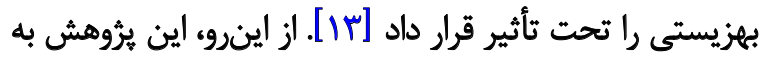

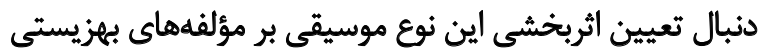

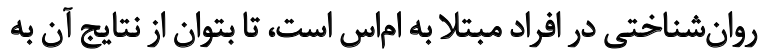
عنوان روشى مكمل در كنار ديخر اقدامات درمانكرى استفاده كرد. با مرورى بر بروهشها، مى توان به مجموعه مطالعات اثربخشى إئى

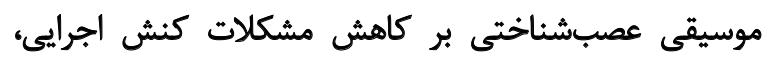

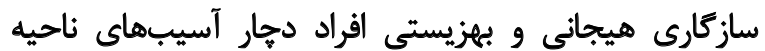

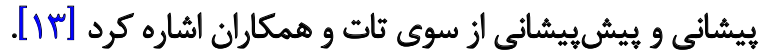

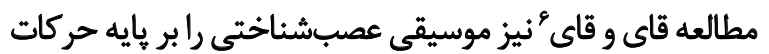

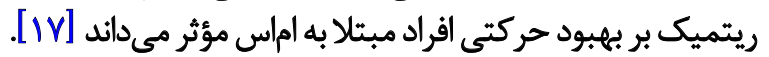

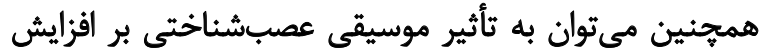

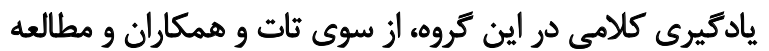

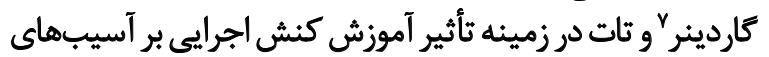

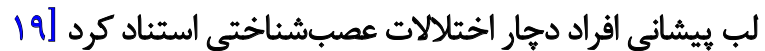

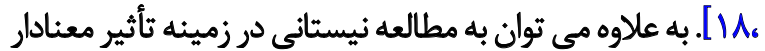

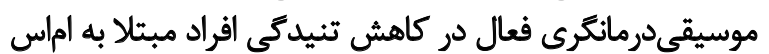

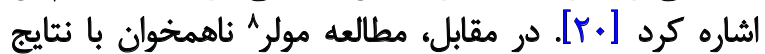

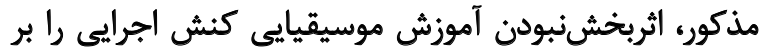

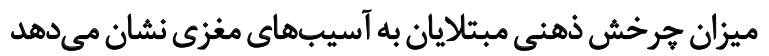

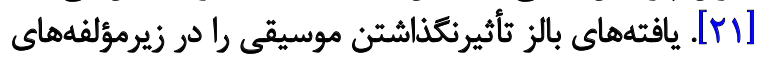

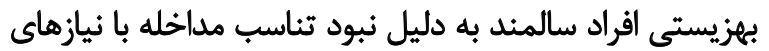

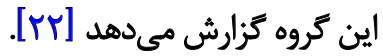

6. Ghai \& Ghai

7. Gardiner

8. Muller 
با مجموع سؤال هاى خردهمقياسها نمره كل به دست مي آيد.

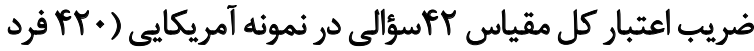

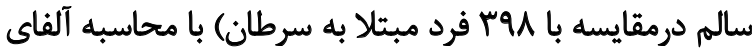

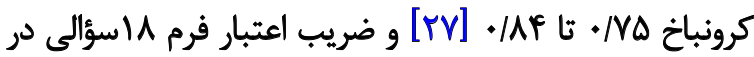

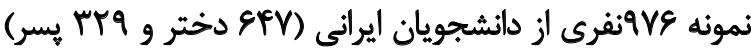

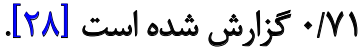

\section{برنامه مداخله موسيقي عصبشناختى}

مداخله موسيقيايى بر اساس هشت عنوان برنامه آموزش

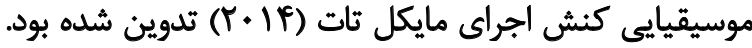

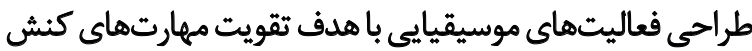

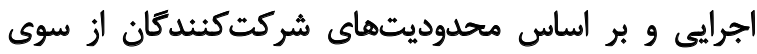

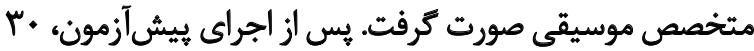

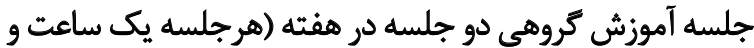

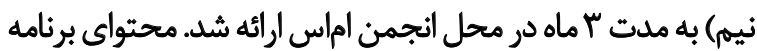

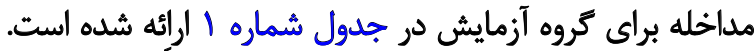

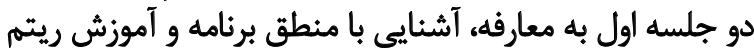

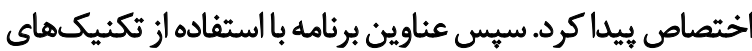

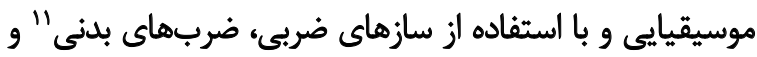

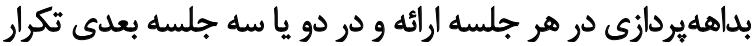

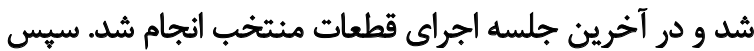

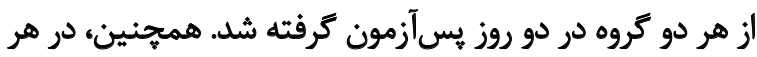

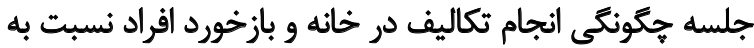

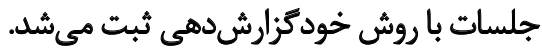

به منظور بررسى اعتبار درونى برنامه از ضريب روايى محتوا

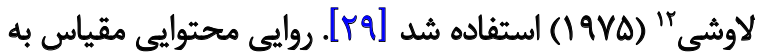

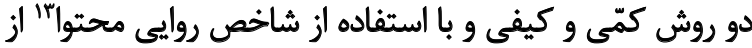

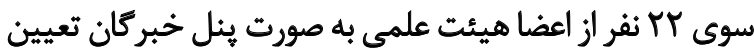

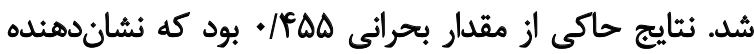
مكفىبودن روايي محتواى برنامه است.

ياقتثلها

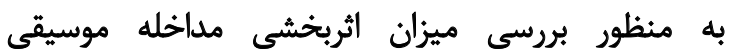

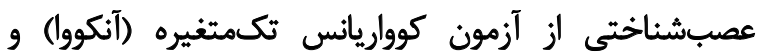

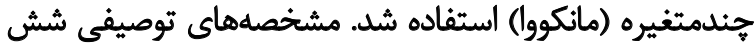

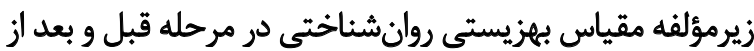

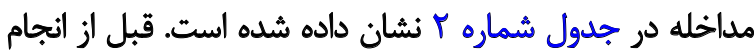

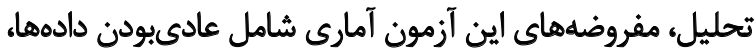

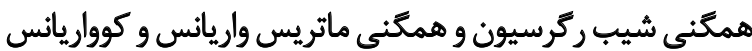

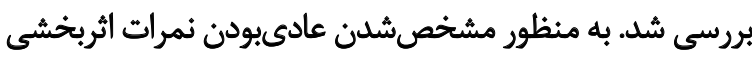

\section{Body percussion}

12. Lawshe

13. Content Validity Index (CVI)

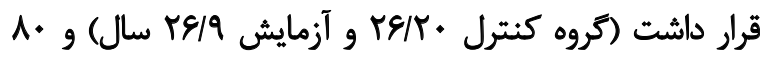

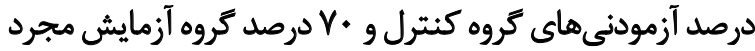

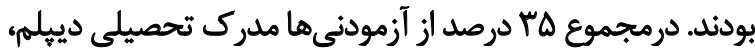

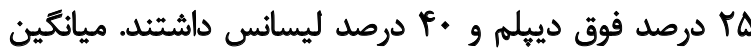

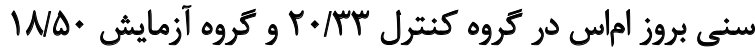

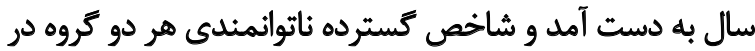

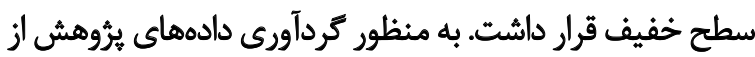

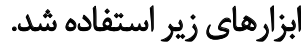
شاحُص تسترده وضعيث ناثوانى اين سياهه راكورتزكه" در سال ب1941 به عنوان يك شاخص

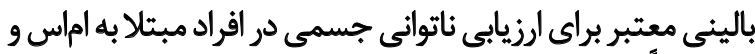

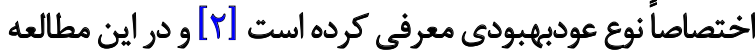

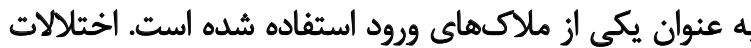

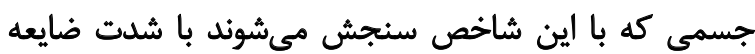
موجود در ساقه مغز و مخجه در ارتباط هستند.

در اين سياهه اطلاعات به كمك سؤالات در زمينه عملكردهاى

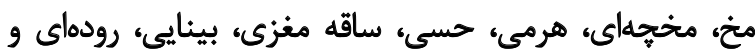

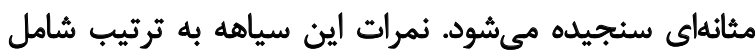

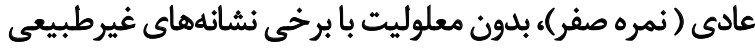

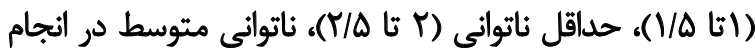

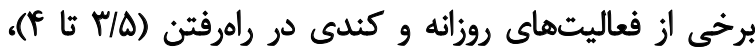

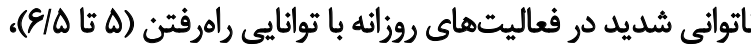

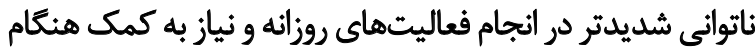

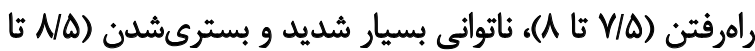

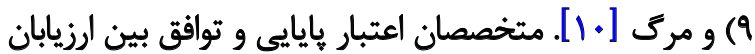

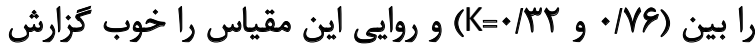

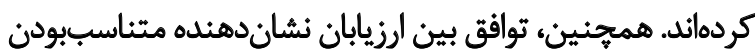

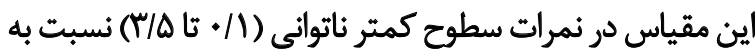

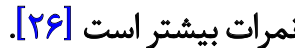

\section{مقياس بجزيستى ووانشئاختى - مئي}

اين يروهش از يرسشنامه فرم كوتاه باسؤالى مقياس

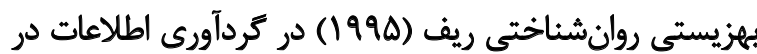

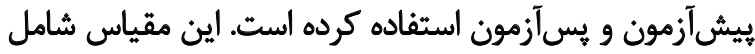

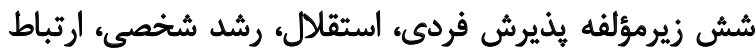

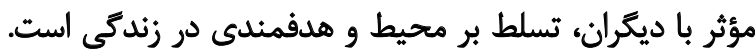

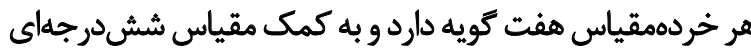

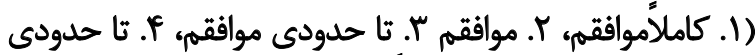

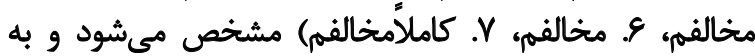

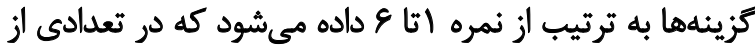

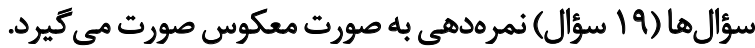

10. kurtzke 


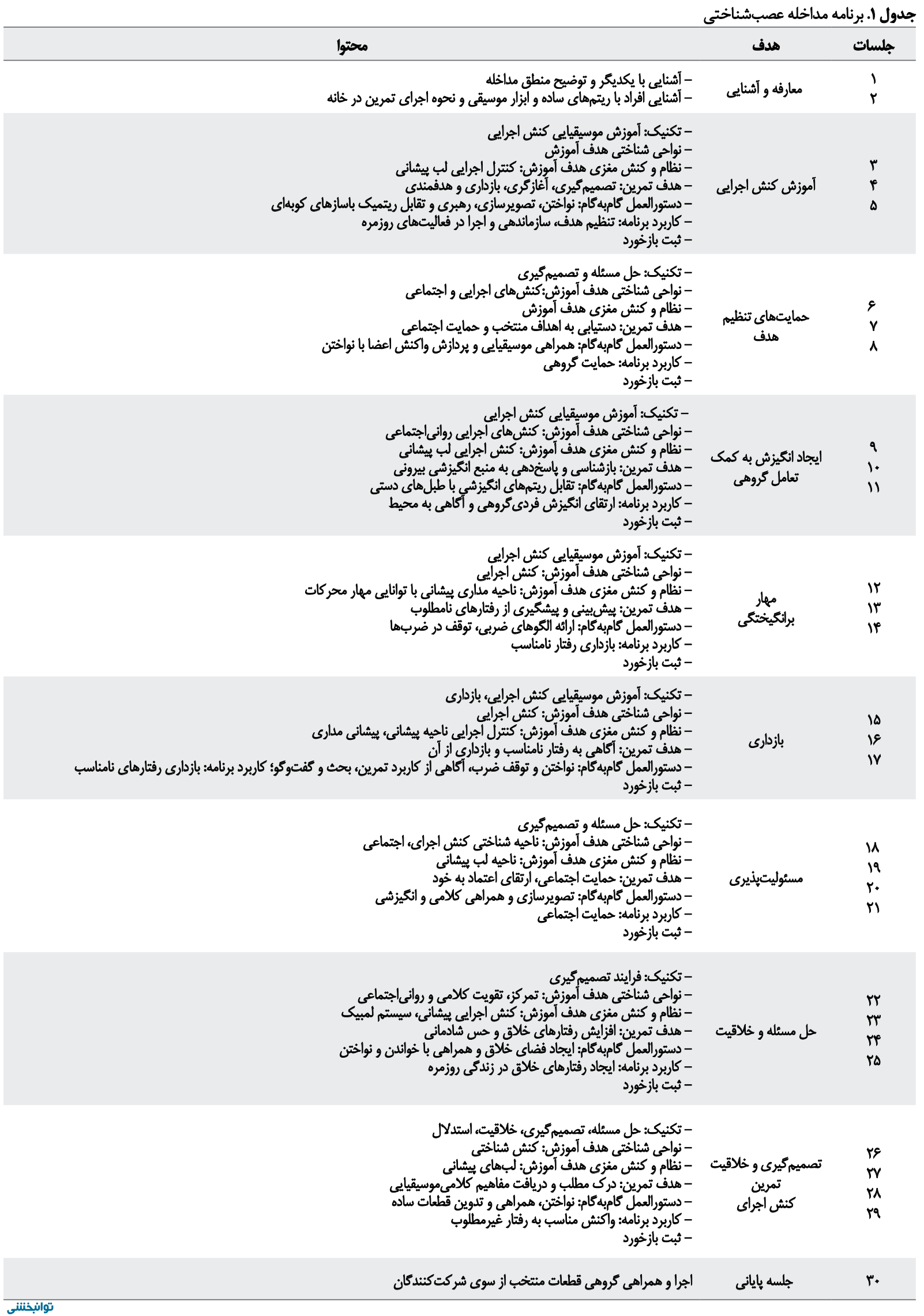


جدول Y. توصيف نمرههاى زيرمؤلفهايى مقياس بهزيستى روانشناختى به ثفكيك كروه كنترل و آزمايش

\begin{tabular}{|c|c|c|c|c|c|}
\hline \multicolumn{2}{|c|}{ تروه آزمايش } & \multicolumn{2}{|c|}{ كروه كتترل } & \multirow{2}{*}{ سطح } & \multirow{2}{*}{ مثغير } \\
\hline انحراف استاندارد & مياتكين & انحراف استاندارد & مياتكين & & \\
\hline$r / N$ & $r e N$ & $r / u$ & $r / r$. & ييشآزهون & \multirow{2}{*}{ استقلال } \\
\hline$r / N$ & rq & $r / N$. & re/r. & بس آزمون & \\
\hline $1 / 49$ & rWls. & T/QT & $r / f *$ & ييش آزمون & \multirow{2}{*}{ ارتباط موثر با ديكران } \\
\hline$r / 4 i$ & rV/F. & T/Eg & $r q /{ }^{\prime}$. & بسآزمون & \\
\hline$F / A r$ & $19 / 1$. & $\Delta / T \lambda$ & $r V / A$. & يشيشآزمون & \multirow{2}{*}{ تسلط بر محيط } \\
\hline$\Delta / * V$ & $M / A_{0}$ & $r / \Lambda *$ & $r$ & بس أزمون & \\
\hline r & $r$ & $\Delta / W$ & $\pi / / 8$. & يش آزمون & \multirow{2}{*}{ رشد شخصى } \\
\hline $\operatorname{siT}$ & To & $\Delta / \varphi^{\circ}$ & $r \cdot 10$. & يس أزمون & \\
\hline r/F & $\pi$ & P/N & $r / \Omega$ & ييش آزمون & \multirow{2}{*}{ هدفمندى در زندكى } \\
\hline$r / . r$ & $\pi / \%$ & $4 / 19$ & $m / f$ & بسآزمون & \\
\hline N/T & $r / N$. & r/qV & $\pi / r$ & ييش آزمون & \multirow{2}{*}{ بذيرش خود } \\
\hline$r / N$ & $\pi / A$. & $r / q 1$ & $\pi / R^{*}$ & بس أزمون & \\
\hline Nar & $1 \% r / 9$. & $1 \% / .4$ & $\| \& \& / 4$. & يشيآزمون & \multirow{2}{*}{ نمره كل } \\
\hline NTr & IFNE. & $\sin$ & IFT/A. & بيسآزمون & \\
\hline
\end{tabular}

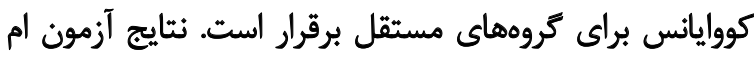

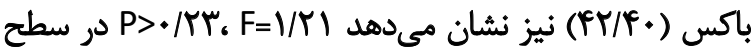

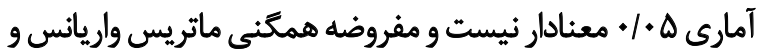
كوواريانس رعايت شده است.

يس از بررسى همه بيشفرض هائى مرتبط با تحليل كوواريانس

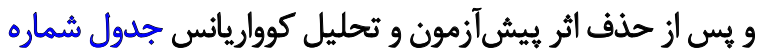

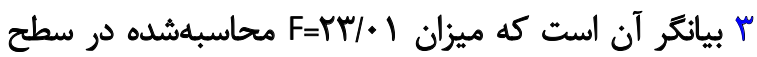

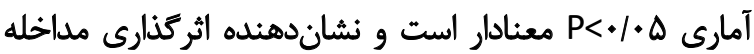

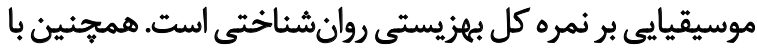

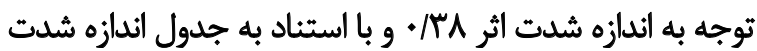

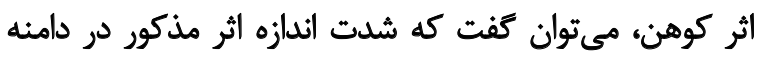
كوخج تا متوسط است.
مداخله موسيقى عصبشناختى در شركت كنندكان مبتلا به

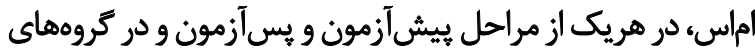

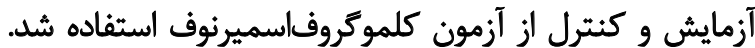

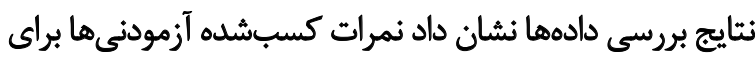

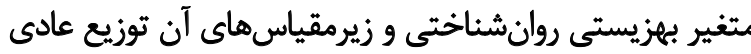

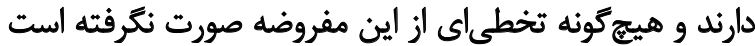

$(\mathrm{P}>\cdot 1 \cdot \Delta)$

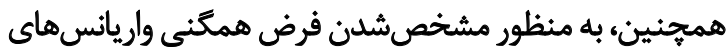

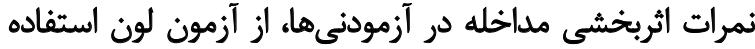

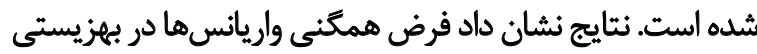

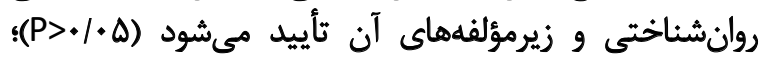

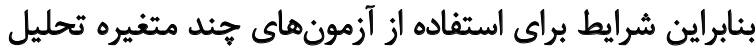

\begin{tabular}{|c|c|c|c|c|c|c|}
\hline اندازه شدت اثير & سطح معنادارى & $\mathbf{F}$ & ميانكين مجذوراث & هرجه آراديى & مجموع مجذوراث & منيع تغييرات \\
\hline.$/ \Delta r$ & $\%$ & $\mathrm{rl} / \mathrm{E}$ & $\Delta 94 / 80$ & 1 & $\Delta q 4 / 80$ & ييشآزمون \\
\hline . & $\%$ & $m / .1$ & tre/fre & 1 & $T V E / T F$ & كروه \\
\hline- & - & - & TA/Ar & iv & $\mathrm{Rrq} / \mathrm{me}$ & خطا \\
\hline
\end{tabular}


جدول P. خلاصه آزمونهاي جندمتغيرى بهزيستي روانشئاختي

\begin{tabular}{|c|c|c|}
\hline سطح معنادارى & $F$ & شاخص آمارى \\
\hline$\%$ &.$/ p v$ & اثر ييلاى \\
\hline$\%$ &.$|x|$ & لامبداى ويلكز \\
\hline. & $. / 1+4$ & تى هاتليئى \\
\hline
\end{tabular}

توانبخننى

\begin{tabular}{|c|c|c|c|c|c|c|}
\hline اندازه شدت اثر & سطح معنادارى & $\mathrm{F}$ & ميانكين مجذورات & درجه أزادى & مجموع مجذورات & منبع تغييرات \\
\hline .1 .9 & $T / N E$ & $1 / 4$ & $9 / 24$ & 1 & $9 / \mu F$ & استقالال \\
\hline.$/ T r$ & $.1 \cdot 1$ & $r / g r$ & 19/9F & 1 & 19/9F & الرتباط موثثر با ديكران \\
\hline $.1 * V$ & 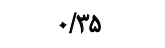 &.$/ 9 Y$ & $11 / 48$ & 1 & $11 / 48$ & تسلط بر محيط \\
\hline.$/ . r$ & . Iar &.$/ 48$ & T/RA & 1 & ג גז/ז & رشد شخصى \\
\hline .1 .1 & .195 & Ir & $T / N$ & 1 & $r / w_{1}$ & هدفهندى در زندكى \\
\hline.$/ 4$ & " r/. & Ir & $r / .9$ & 1 & $r / * 9$ & يذيرش خود \\
\hline
\end{tabular}

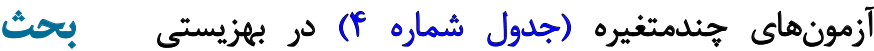
براى آماره

هدف از اين بثوهش، بررسى اثربخشى موسيقى عصبشناختى

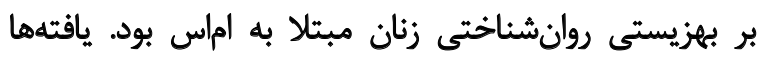

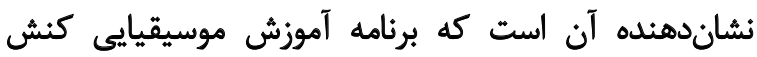

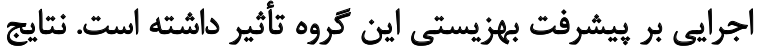

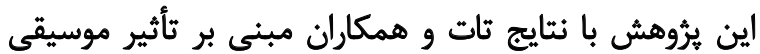

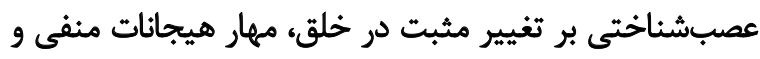

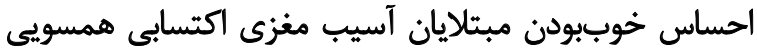

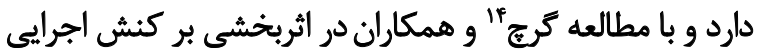

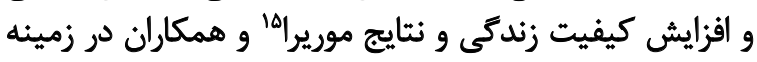

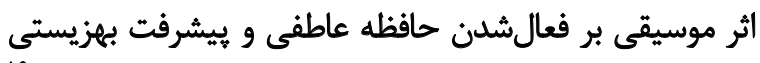

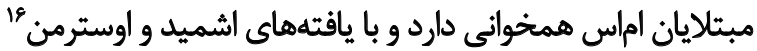

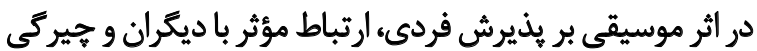

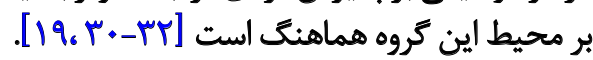

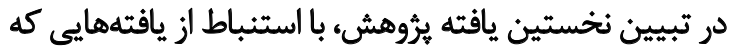

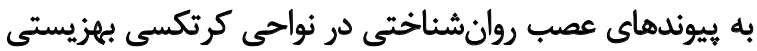

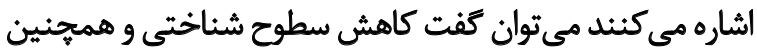

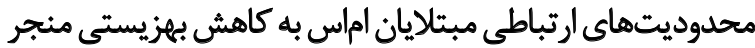

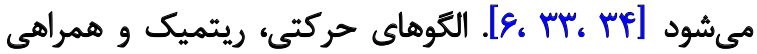

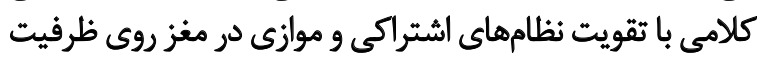

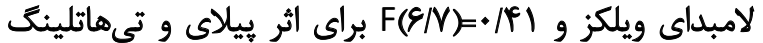

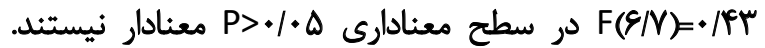

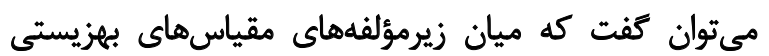

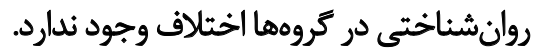
همان كونه كه در جدول شماره ه نمايش داده شده است،

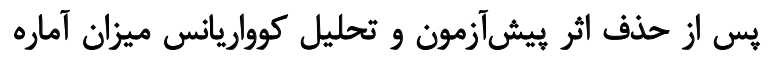

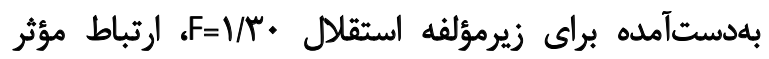

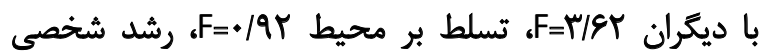

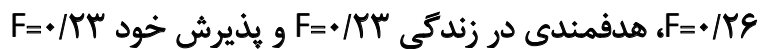

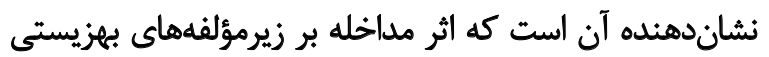

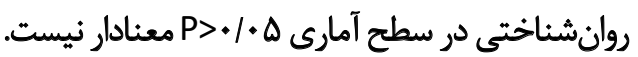

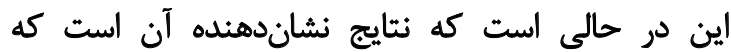

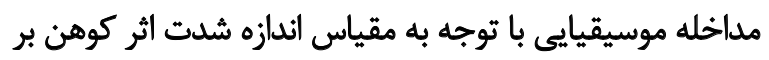

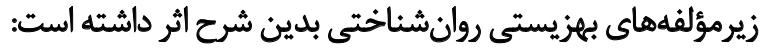

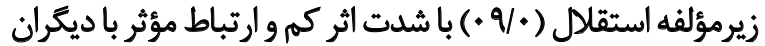

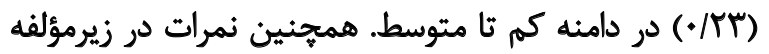

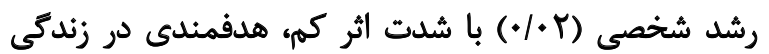

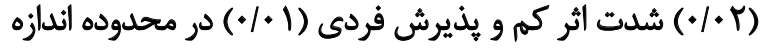

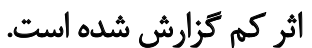


اين افراد در زندكى روزمره شده است [ب. [Y.]] اثر مداخله موسيقيايى بر رشد شخصى با اندازه اثر بسيار كم

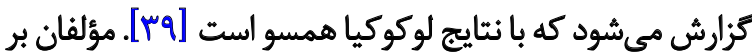

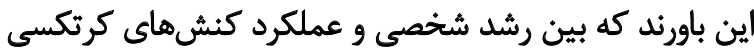

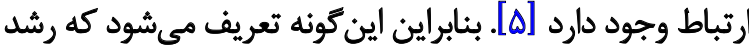

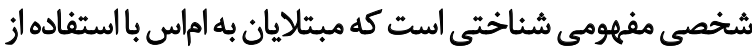

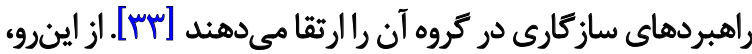

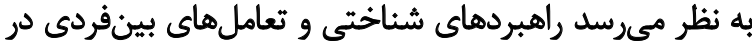
اين مداخله امكان رشد شخصى را فراهم شنم آورده است.

مداخله موسيقيايى بر هدفمندى در زندگى به مئ ميزان بسيار

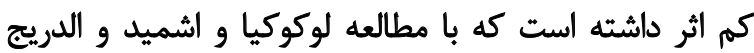

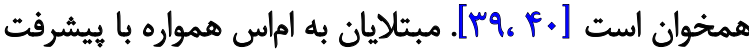

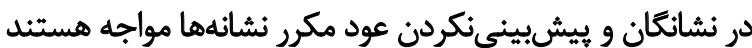

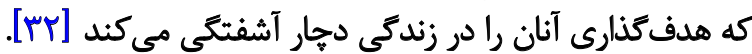

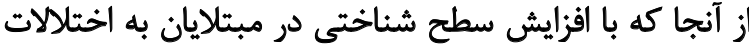

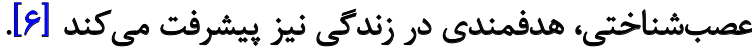

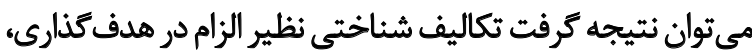

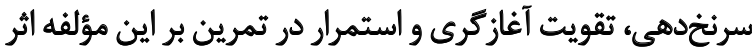

داشته است [19]

نتايج حاكى از اثر مداخله بر هذيرش فردى به ميزان بسيار

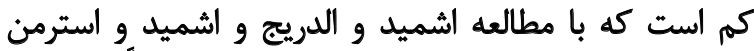

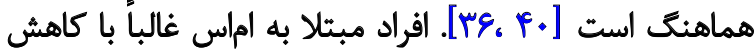

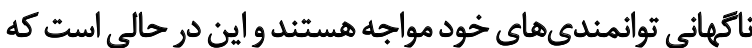

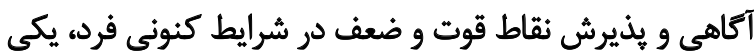

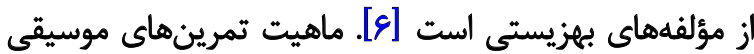

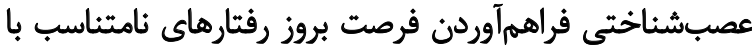

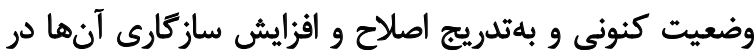

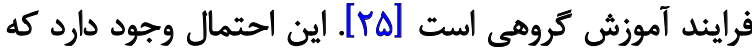

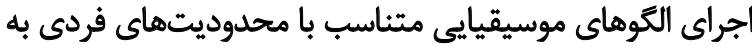
درى تصوير كنونى و يذيرش شرايط إئ واقعى به آنان كمك كرده

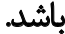

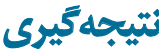

نتايج اين بروهش نشان داد مداخله موسيقى عصبش فشناختى

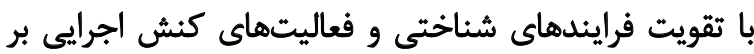

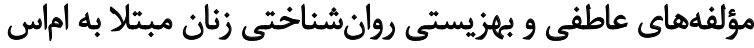

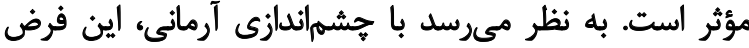

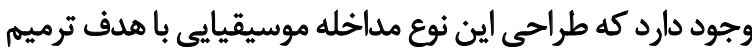

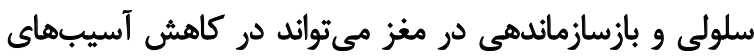
عصبشناختى مبتلايان به اماس كاربرد داشته باشئ باشد.

بيشنهاد اين بُروهش با استناد به تحقيقات بيشين [.1]، بهكارستن همزمان مداخله بهزيستى روانشناختى و مداخله
طبقهبندى، انعطافيذيرى ذهنى و خودتنظيمى اثر مي كذارد و

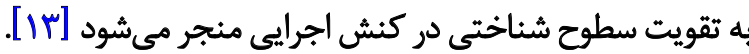

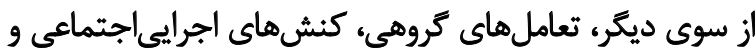

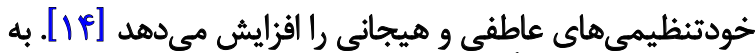

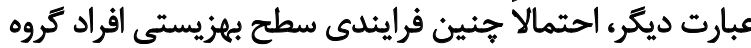
آزمايش را افزايش داده است.

درباره تحليل نتايج دوم يرؤهش، نخست به اين نكته اشاره

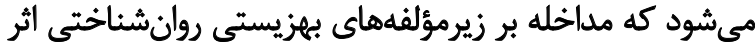

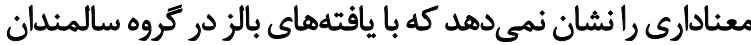

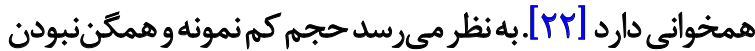

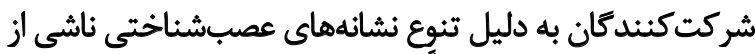

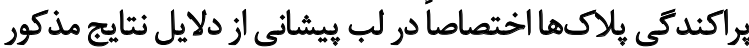

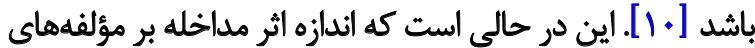

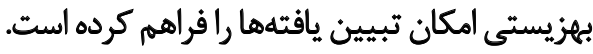

تحليل دادهها نشان مى دهد مداخله بر استقلال فردى به به بائ

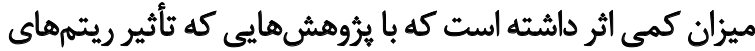

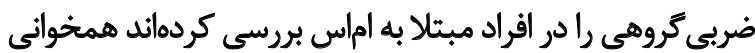

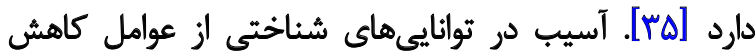

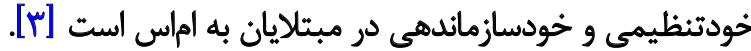

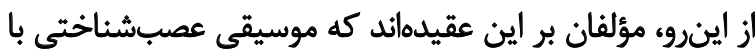

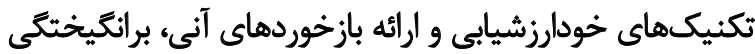

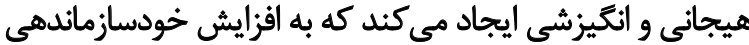

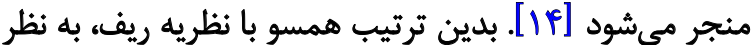
ميرسد مداخله با تأثير بر هينين فرئين فرايندى، امكان استقلال

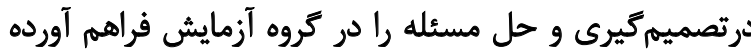

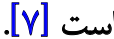

در تبيين اثربخشى مداخله بر ارتباط مؤثر بر ديكران به ميزان

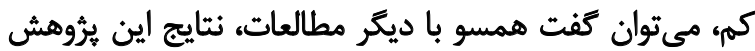

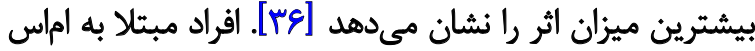

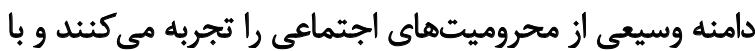

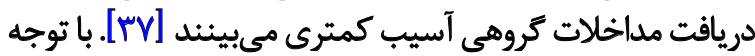

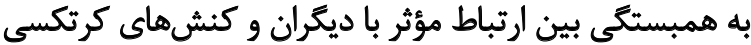

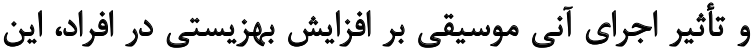

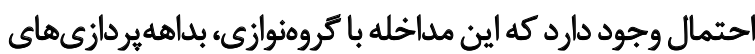

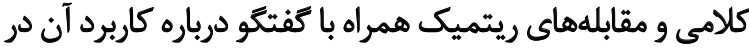

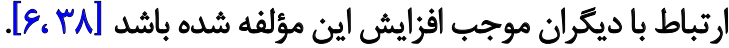
مداخله بر مؤلفه تسلط بر محيط با شدت كم اثر داشته است

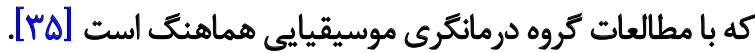

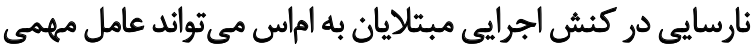

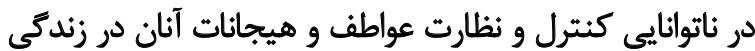

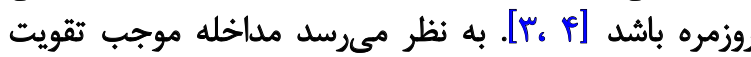

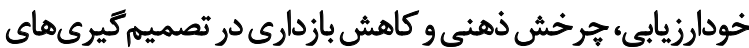


موسيقيايى به منظور اثربخشى بيشتر است. مقايسه تفاوت

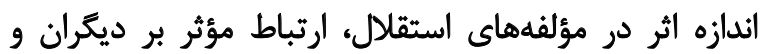

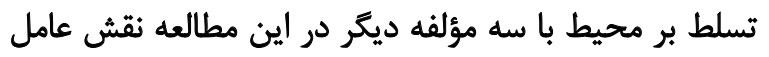

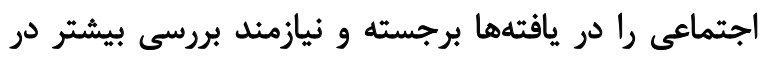

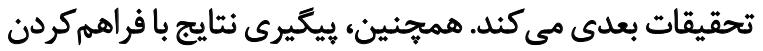

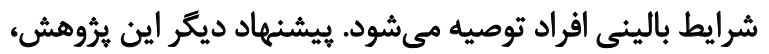

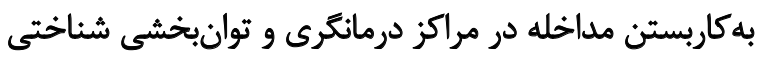

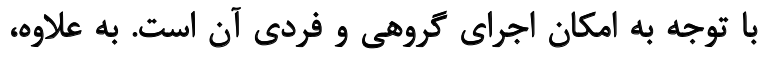

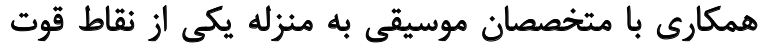

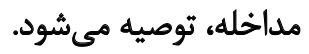

خلأ بيشينه تحقيقاتى در ايران، انجامنشدن آزمون بي بيكيرى

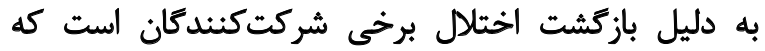

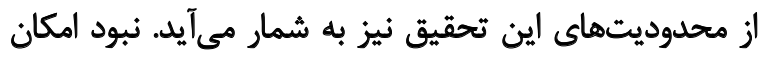

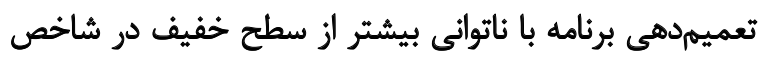

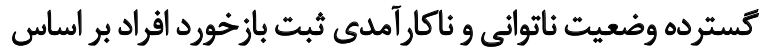

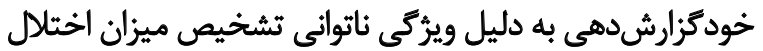

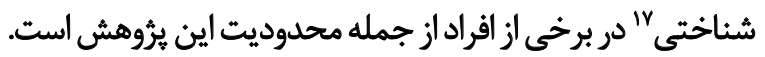

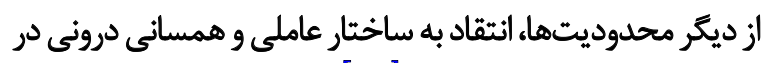

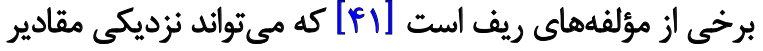
اندازه اثر را در برخى از مؤلفهها تحت تأثير قرار دهد.

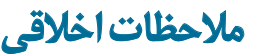

يبروى أز اصول اخلاق يُوهنش

براى رعايت اصول اخلاقىه ازكليه شركت كنند أنان رضايتنامه

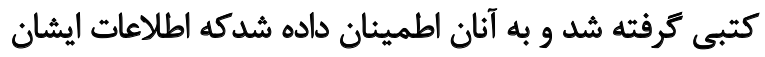

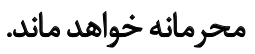

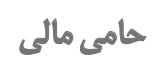

مقاله حاضر از رساله دكترى فرحناز نورمحمدى دانشجوى إني

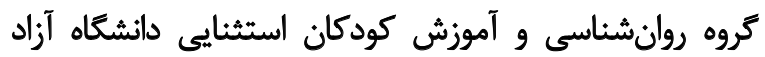
اسلامى واحد علوم و تحقيقات تهران كرفته شده است.

$$
\text { مشاركت ثويسند انتان }
$$

تمام نويسندكان در آمادهسازى اين مقاله مشاركت داشتهاند.

$$
\text { تقعار منأع }
$$

بنابر اظهار نويسندكان، اين مقاله تعارض منافع ندارد. 


\section{References}

[1] Eskandarieh S, Heydarpour P, Minagar A, Pourmand S, Sahraian MA. Multiple Sclerosis epidemiology in East Asia, South East Asia and South Asia: A systematic review. Neuroepidemiology. 2016; 46(3):209-21. [DOI:10.1159/000444019] [PMID]

[2] Huang WJ, Chen WW, Zhang X. Multiple Sclerosis: Pathology, diagnosis and treatments. Experimental and Therapeutic Medicine. 2017; 13(6):3163-6. [DOI:10.3892/etm.2017.4410] [PMID] [PMCID]

[3] Guimarães J, Sá MJ. Cognitive dysfunction in Multiple Sclerosis. Frontiers in Neurology. 2012; 3(74):1-8. [DOI:10.3389/ fneur.2012.00074] [PMID] [PMCID]

[4] Shiri V, Emami M, Shiri E. [Investigating the relationship between selective attention and cognitive flexibility with balance in patients with relapsing-remitting Multiple Sclerosis (Persian)]. Archives of Rehabilitation. 2018; 18(4):296-305. [DOI:10.21859/jrehab.18.4.4]

[5] Lopez SJ, Pedrotti JT, Snyder CR. Positive psychology: The scientific and practical explorations of human strengths. Thousand Oaks, California: Sage Publications; 2018.

[6] Ryff CD. Psychological well-being revisited: Advances in the science and practice of eudaimonia. Psychotherapy and Psychosomatics. 2014; 83(1):10-28. [DOI:10.1159/000353263] [PMID] [PMCID]

[7] Lopez Gomez I, Chaves C, Hervas G, Vazquez C. Comparing the acceptability of a positive psychology intervention versus a cognitive behavioural therapy for clinical depression. Clinical Psychology \& Psychotherapy. 2017; 24(5):1029-39. [DOI:10.1002/cpp.2129] [PMID]

[8] Kringelbach ML, Berridge KC. The affective core of emotion: linking pleasure, subjective well-being, and optimal metastability in the brain. Emotion Review. 2017; 9(3):191-9. [DOI:10.1177/1754073916684558] [PMID] [PMCID]

[9] Strober L. Well-Being and Perceived Health in Multiple Sclerosis (MS): The Role of Personality. Journal of Multiple Sclerosis. 2017; 4(205):2376-89. [DOI:10.4172/2376-0389.1000205]

[10] Weiss LA, Westerhof GJ, Bohlmeijer ET. Can we increase psychological well-being? The effects of interventions on psychological well-being: A meta-analysis of randomized controlled trials. PLOS ONE. 2016; 11(6):e0158092. [DOI:10.1371/journal.pone.0158092] [PMID] [PMCID]

[11] Pagnini F, Bosma CM, Phillips D, Langer E. Symptom changes in Multiple Sclerosis following psychological interventions: A systematic review. BMC Neurology. 2014; 14(1):222. [DOI:10.1186/s12883-014-0222-z] [PMID] [PMCID]

[12] Thaut MH, McIntosh GC, Hoemberg V. Neurobiological foundations of neurologic music therapy: Rhythmic entrainment and the motor system. Frontiers in Psychology. 2015; 5(1185):1-6. [DOI:10.3389/fpsyg.2014.01185]

[13] Thaut MH MG, Hoemberg V. Handbook of neurologic music therapy, $2^{\text {nd }}$ ed. Oxford: Oxford University Press; 2016.
[14] Galińska E. Music therapy in neurological rehabilitation settings. Psychiatria Polska. 2015; 49(4):835-46. [DOI:10.12740/ PP/25557] [PMID]

[15] Whitehead JC, Armony JL. Singing in the brain: Neural representation of music and voice as revealed by fMRI. Human Brain Mapping. 2018; 39(12):4913-24. [DOI:10.1002/ hbm.24333] [PMID]

[16] Malcomson KS, Dunwoody L, Lowe-Strong AS. Psychosocia interventions in people with multiple sclerosis. Journal of Neurology. 2007; 254(1):1-13. [DOI:10.1007/s00415-006-0349-y] [PMID]

[17] Ghai S, Ghai I. Effects of rhythmic auditory cueing in gait rehabilitation for Multiple Sclerosis: A mini systematic review and meta-analysis. Frontiers in Neurology. 2018; 9(386):1-14. [DOI:10.3389/fneur.2018.00386]

[18] Thaut MH, Peterson DA, Sena KM, Mcintosh GC. Musical structure facilitates verbal learning in Multiple Sclerosis. Music Perception: An Interdisciplinary Journal. 2008; 25(4):325-30. [DOI:10.1525/mp.2008.25.4.325]

[19] Thaut MH, Gardiner JC, Holmberg D, Horwitz J, Kent L, Andrews $\mathrm{G}$, et al. Neurologic music therapy improves executive function and emotional adjustment in traumatic brain injury rehabilitation. Annals of the New York Academy of Sciences. 2009; 1169(1):406-16. [DOI:10.1111/j.17496632.2009.04585.x] [PMID]

[20] Neyestanee MH, Dabbaghee P, Zandyfar H. [Effectiveness of music therapy on reducing stress in patients with MS: Clinical research (Persian)]. Paper presented at the $11^{\text {th }}$ MS Congress of Iran. 23-24 October 2014; Tehran, Iran.

[21] Mueller C. Training endogenous task shifting using neurologic music therapy [PhD. dissertation]. Libraries: Colorado State University; 2013

[22] Bowles SL. Memory, cognition, and the effect of a music intervention on healthy older adults [PhD. dissertation]. Lexington, Kentucky: University of Kentucky; 2013.

[23] Moosazadeh M, Esmaeili R, Mehdi Nasehi M, Abedi G, Afshari $\mathrm{M}$, Farshidi $F$, et al. Prevalence of familial Multiple Sclerosis in Iran: A systematic review and meta-analysis. Iranian Journal of Neurology. 2017; 16(2):90-5. [PMID] [PMCID]

[24] Sesel AL, Sharpe L, Naismith SL. Efficacy of psychosocial interventions for people with Multiple Sclerosis: A meta-analysis of specific treatment effects. Psychotherapy and Psychosomatics. 2018; 87(2):105-11. [DOI:10.1159/000486806] [PMID]

[25] Raglio A, Attardo L, Gontero G, Rollino S, Groppo E, Granieri $\mathrm{E}$. Effects of music and music therapy on mood in neurological patients. World Journal of Psychiatry. 2015; 5(1):68-78. [DOI:10.5498/wjp.v5.i1.68] [PMID] [PMCID]

[26] Meyer Moock S, Feng YS, Maeurer M, Dippel FW, Kohlmann T. Systematic literature review and validity evaluation of the Expanded Disability Status Scale (EDSS) and the Multiple Sclerosis Functional Composite (MSFC) in patients with Multiple Sclerosis. BMC Neurology. 2014; 14(1):58. [DOI:10.1186/14712377-14-58] [PMID] [PMCID] 
[27] Springer KW, Hauser RM, Freese J. Bad news indeed for Ryff's six-factor model of well-being. Social Science Research. 2006; 35(4):1120-31. [DOI:10.1016/j.ssresearch.2006.01.003]

[28] Khanjani M, Shahidi S, Abadi.J. F, Mazaheri M, Shokri A. [Factor structure and psychometric properties of the Ryff's scale of Psychological well-being, short form (18-item) among male and female students (Persian)]. Thought and Behavior in Clinical Psychology. 2014; 8(32):27-36.

[29] Kesahan M, Mepi K, Nisbah M, Kandungan K, Mohd Noor N, Aziz Shah M, et al. Measuring the Content Validity of MEPI using Content Validity Ratio. Journal of ICT in Education. 2016; 3:81-8.

[30] Thaut MH, Gardiner JC, Holmberg D, Horwitz J, Kent L, Andrews $G$, et al. Neurologic music therapy improves executive function and emotional adjustment in traumatic brain injury rehabilitation. Annals of the New York Academy of Sciences. 2009; 1169(1):406-16. [DOI:10.1111/j.17496632.2009.04585.x] [PMID]

[31] Grech LB, Kiropoulos LA, Kirby KM, Butler E, Paine M, Hester R. Importance of coping in the relationship between executive function and quality of life in people with Multiple Sclerosis. International Journal of MS Care. 2018; 20(3):109-19. [DOI:10.7224/1537-2073.2018-029] [PMID] [PMCID]

[32] Moreira SV, França CC, Moreira MA, Lana-Peixoto MA. Musical identity of patients with Multiple Sclerosis. Arquivos de Neuro-Psiquiatria. 2009; 67(1):46-9. [DOI:10.1590/50004282X2009000100012] [PMID]

[33] Ostermann T, Schmid W. Music therapy in the treatment of Multiple Sclerosis: A comprehensive literature review. Expert Review of Neurotherapeutics. 2006; 6(4):469-77. [DOI:10.1586/14737175.6.4.469] [PMID]

[34] Park CL. Making sense of the meaning literature: An integrative review of meaning making and its effects on adjustment to stressful life events. Psychological Bulletin. 2010; 136(2):257301. [DOI:10.1037/a0018301] [PMID]

[35] Heintzelman S. Eudaimonia in the contemporary science of subjective well-being: Psychological well-being, self-determination, and meaning in life. In: Diener E, Oishi S, Tay L, editors. Handbook of Well-Being. Salt Lake City, UT: DEF Publishers; 2018.

[36] Ascenso S, Perkins R, Atkins L, Fancourt D, Williamon A. Promoting well-being through group drumming with mental health service users and their carers. International Journal of Qualitative Studies on Health and Well-Being. 2018; 13(1):1484219. [DOI:10.1080/17482631.2018.1484219] [PMID] [PMCID]

[37] Schmid W, Ostermann T. Home-based music therapy: A systematic overview of settings and conditions for an innovative service in healthcare. BMC Health Services Research. 2010; 10(1):291. [DOI:10.1186/1472-6963-10-291] [PMID] [PMCID]

[38] Barker AB, Lincoln NB, Hunt N, dasNair R. Social Identity in People with Multiple Sclerosis: An examination of family identity and mood. International Journal of MS Care. 2018; 20(2):8591. [DOI:10.7224/1537-2073.2016-074] [PMID] [PMCID]
[39] Särkämö T, Altenmüller E, Rodríguez-Fornells A, Peretz I. Editorial: Music, brain, and rehabilitation: Emerging therapeutic applications and potential neural mechanisms. Frontiers in Human Neuroscience. 2016; 10(103):1-5. [DOI:10.3389/fnhum.2016.00103]

[40] Laukka P. Uses of music and psychological well-being among the elderly. Journal of Happiness Studies. 2007; 8(2):215-41. [DOI:10.1007/s10902-006-9024-3]

[41] Schmid W, Aldridge D. Active music therapy in the treatment of multiple sclerosis patients: A matched control study. Journal of Music Therapy. 2004; 41(3):225-40. [PMID]

[42] Springer KW, Hauser RM. An assessment of the construct validity of Ryff's scales of psychological well-being: Method, mode, and measurement effects. Social Science Research. 2006; 35(4):1080-102. [DOI:10.1016/j.ssresearch.2005.07.004] 